\title{
Acción exterior y propaganda. Las visitas de líderes latinoamericanos a Franco
}

\author{
Matilde Eiroa San Francisco*
}

RESUMEN: En este artículo se aborda el análisis de uno de los instrumentos de acción exterior del franquismo desde 1939 hasta 1975, concretamente las visitas de dirigentes latinoamericanos concebidas como grandes operaciones políiticas, propagandísticas y de relaciones públicas. De todas las que se produieron, hemos seleccionado tres casos de gran relevancia y repercusión política y mediática: el de Eva Perón, Rafael Leónidas Trujillo y Alfredo Stroessner.

Palabras clave: Políitica exterior, Propaganda, Franquismo, Eva Perón, Rafael Leónidas Trujillo, Alfredo Stroessner.

ABSTRACT: This article deals with the analysis of one common practice of the Spanish Francoist regime from 1939 until 1975, specifically the visits of Latin American leaders, intended as a major political propaganda operations and public relations. Among all those visits, we have selected three cases of far-reaching relevance in politics and in the media: Eva Perón, Rafael Leónidas Trujillo and Alfredo Stroessner.

Key words: Foreign Policy, Propaganda, Francoism, Eva Perón, Rafael Leónidas Trujillo, Alfredo Stroessner.

\footnotetext{
Universidad Carlos III, Madrid (meiroa@hum.uc3m.es).
} 


\section{INTRODUCCIÓN}

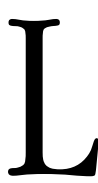

a acción exterior es uno de los ámbitos más importantes de la política exterior y puede ejecutarse a través de actuaciones en el campo de la economía, la cultura, la propaganda, la diplomacia o cualquier otra actividad de relaciones públicas. Resulta necesario, sin embargo, diferenciar este concepto del término política exterior y relaciones internacionales. Ante todo, la política exterior es una parcela singular de la política general de cada Estado y podríamos definirla, siguiendo a R. Calduch, como "aquella parte de la política general formada por un conjunto de decisiones y actuaciones mediante las que se definen los objetivos y se utilizan los medios de un Estado para generar, modificar o suspender sus relaciones con otros actores de la sociedad internacional". ${ }^{1}$ Las relaciones internacionales, en cambio, abarcan una amplia gama de correspondencias entre estados, pueblos y grupos organizados en un ámbito espacial determinado, el de la sociedad internacional. Tal como indica la historiografía francesa, especialmente P. Renouvin y J. B. Duroselle, en la política exterior y en las relaciones internacionales actúan no sólo los estados, sino las "fuerzas profundas" de éstos, a saber, grupos de presión económica, la opinión pública, los medios de comunicación, las mentalidades colectivas, los nacionalismos, las fuerzas armadas o la cultura. En definitiva, visiones e intereses múltiples que generan lazos políticos de distinta tipología. ${ }^{2}$ Según esta conceptualización, entendemos que el franquismo tuvo política exterior y desarrolló una acción subordinada a sus intereses, entre los que ha de subrayarse la supervivencia en el poder de su principal protagonista.

En las páginas que siguen, analizaremos uno de los instrumentos de la acción exterior de España desde 1939 hasta 1975, concretamente las visitas y encuentros de personalidades y representaciones políticas latinoamericanas. En este sentido proponemos una relación estrecha entre acción exterior y propaganda, definida según A. Pizarroso como una forma de comunicación persuasiva

1 Rafael Calduch, "La política exterior de los Estados", en Juan Carlos Pereira [coord.], La política exterior de España (1800-2003), Barcelona, Ariel, 2003, pp. 31-55.

2 Un estudio de ambos, en Pierre Renouvin y Jean Baptiste Duroselle, Introducción a la bistoria de las relaciones internacionales, México, FCE, 2000. 
ideológica, que enmarca los mensajes con una orientación particular, reductora y partidista. La propaganda es el lenguaje de los imperativos categóricos, algo que no se discute y está sujeto a la manipulación con tal de alcanzar sus objetivos. ${ }^{3}$ La relación entre acción exterior y propaganda franquista es estrecha en cuanto que ambas contribuyeron a la ejecución de objetivos, tales como la proyección positiva del régimen y la imagen idealizada de su jefe de Estado.

El continente latinoamericano ha sido uno de los principales objetos de estudio de los historiadores interesados en las relaciones internacionales de la España de Franco. Numerosos investigadores han profundizado desde hace tiempo en el estudio del "hispanoamericanismo" y la "hispanidad" desde perspectivas y temáticas distintas. ${ }^{4}$ En los últimos años se han publicado estudios específicos y análisis de conjunto que muestran la evolución del régimen en relación con los distintos actores y factores que contribuyeron a perfilar su identidad. En este sentido son dignas de mención las obras coordinadas por Juan Carlos Pereira, Ricardo Miralles, Florentino Portero o Encarnación Lemús, estructuradas como estudios de todos los elementos que definen la política exterior española. ${ }^{5}$ Con-

3 Alejandro Pizarroso, "Historia de la propaganda: una aproximación metodológica", en Historia y comunicación social, núm. 4, 1999, pp. 145-171. Alonso Méndiz Noguero, "Diferencias conceptuales entre publicidad y propaganda: una aproximación etimológica", en Questiones publicitarias, vol. I, núm. 12, 2007, pp. 43-61.

4 Algunos estudios del extenso catálogo que componen las investigaciones sobre el tema son: Eduardo González Calleja y otros, La Hispanidad como instrumento de combate. Raza e Imperio en la prensa franquista durante la Guerra Civil española, Madrid, CSIC, 1988. Montserrat Huguet, "El concepto de la hispanidad en el franquismo en la inmediata posguerra (1939-1945)", en Varios autores, Inmigración, integración e imagen de los latinoamericanos en España (1939-1945). Apuntes introductorios, Madrid, oEI, 1988. Silvia Enrich, Historia diplomática entre España e Iberoamérica en el contexto de las relaciones internacionales (1955-1985), Madrid, Cultura Hispánica, 1989. Celestino del Arenal, España e Iberoamérica. De la Hispanidad a la comunidad iberoamericana de naciones, Madrid, Cedeal, 1989. Del mismo autor, La comunidad iberoamericana de naciones. Pasado, presente y futuro de la política iberoamericana de España, Madrid, Cedeal, 1992. Asimismo, La política exterior de España hacia Iberoamérica, Madrid, Editorial Complutense, 1994.

5 Véase Juan Carlos Pereira [coord.], "La Historia de las Relaciones Internacionales", en Ayer, núm. 42, 2001. Del mismo autor, La política exterior de España (1800-2003), Barcelona, Ariel, 2003. Juan Carlos Pereira y Ricardo Miralles [coords.], "Franquismo, política exterior y memoria histórica", en Historia contemporánea, Universidad del País Vasco, vol. I, núm. 30, 2005. 
sideramos, sin embargo, que quedan aún muchos aspectos que merecen una atención pormenorizada para avanzar en el conocimiento mutuo, de ahí que presentemos este trabajo formando parte de un estudio más amplio sobre las relaciones bilaterales y multilaterales entabladas por el franquismo. ${ }^{6}$ Nuestro objetivo es, en consecuencia, analizar la acción exterior hacia Iberoamérica a través del hilo conductor de las cumbres celebradas entre jefes de Estado, un enfoque novedoso para el que hemos utilizado fondos documentales inéditos, depositados en el Archivo del Palacio Real y en la Fundación Francisco Franco.

\section{LA ORIENTACIÓN HACIA IBEROAMÉRICA:}

\section{LOS INTENTOS DE RECUPERACIÓN DE UN PASADO COMÚN}

La aproximación a las antiguas colonias no fue una innovacion del gobierno de 1939, sino más bien una constante de la política exterior desde los tiempos de la Restauración. El Nuevo Estado franquista le dio un perfil relacionado con la idea de que las naciones latinoamericanas y España formaban una singular colectividad, regulada por un orden común de valores cristianos y tradición que había que explotar en el marco hostil de la posguerra, teniendo en cuenta que Madrid se hallaba en 1945 en una de las peores épocas, internacionalmente hablando, rechazada por Occidente y vagando prácticamente sola en las aguas de las nuevas instituciones mundiales.

La Hispanidad y el pasado común pasaron a ser los argumentos centrales en la explicación de las causas de esa firme tendencia de proyección de una política exterior hacia Latinoamérica. ${ }^{7}$ El objetivo más relevante era la recupera-

Igualmente, Florentino Portero, "La política exterior de España en el siglo xx", en Ayer, núm. 49, 2003; Encarnación Lemús y Rosa Pardo, "La política exterior al final del franquismo", en Historia del Presente, vol. II, núm. 6, 2005.

6 Se trata del libro de la autora del presente artículo, Política internacional y comunicación en España. Las cumbres de Franco con jefes de Estado (1939-1975), Madrid, Ministerio de Asuntos Exteriores y Cooperación, 2009.

7 Lorenzo Delgado Gómez-Escalonilla, Diplomacia franquista y política cultural hacia Iberoamérica, 1939-1953, Madrid, csic, 1988. Del mismo autor, Imperio de papel. Acción cultural y política exterior durante el primer franquismo, Madrid, CSIC, 1992. Marisa González de Oleada, 
ción de la influencia cultural y política en los países latinoamericanos, basándose en la existencia de la misma tradición, historia, lengua y religión. La onu se vislumbraba como el escenario donde poner en marcha una iniciativa de integración de ambas zonas del Atlántico a través de los resortes de la historia y el cristianismo, aunque España no formaba parte de esta organización, y en el contexto de 1946 la mayor parte de los estados habían apoyado las resoluciones aprobadas contra España. Venezuela, Panamá, México, Guatemala y Chile propusieron una ruptura en bloque mientras que Argentina y la República Dominicana rechazaron las propuestas planteadas contra el gobierno de Franco. ${ }^{8} \mathrm{La}$ Hispanidad, sin embargo, no se aplicaría del mismo modo a lo largo de la prolongada duración del régimen, y atravesó diversas fases acomodándose a las circunstancias ideológicas y económicas que concurrieron en cada momento.

En un contexto, pues, poco propicio para el franquismo, una de las acciones más importantes de la política exterior fue organizar encuentros con jefes de Estado. Se trataba de practicar las relaciones públicas con el propósito de incrementar la popularidad, mejorar la imagen y conformar redes internacionales de apoyo. En el caso del régimen de Franco creaban un valor intangible significativo, ya que las actuaciones en este ámbito servían para sacarlo del silencio al que estaba sometido desde que Naciones Unidas recomendó la retirada de los embajadores en 1946. El gobierno consideró una actuación propagandística muy fructífera y positiva el hecho de departir sobre cuestiones internacionales, y aprovechar la estancia a fin de exhibir ante los extranjeros los logros franquistas con breves viajes a ciudades seleccionadas a tal efecto. Las visitas se concibieron como una buena oportunidad de mostrar que Madrid era una alternativa diferente pero válida res-

El doble juego de la Hispanidad. España y Argentina durante la Segunda Guerra Mundial, Madrid, uNED, 2001, pp. 192 y 193, con una tabla de acciones de Hispanidad.

8 Alberto Lleonart Anselem, España y la ONU II (1947): la "cuestión española". Estudio introductorio y corpus documental, Madrid, CSIC, 1983. A favor de la retirada de embajadores votaron Bolivia, Brasil, Chile, Guatemala, Panamá, México, Nicaragua, Paraguay, Uruguay y Venezuela. En contra votaron Argentina, El Salvador, Costa Rica, República Dominicana, Perú y Ecuador. Colombia, Cuba y Honduras decidideron abstenerse. Por tanto, Argentina y República Dominicana no retiraron a sus embajadores cuando se aprobó la resolución, además de Portugal, Suiza y el Vaticano. 
pecto a las demás formas políticas. Los encuentros, pues, se organizaron con gran profusión de actos sociales y con la presencia masiva de medios de comunicación, quienes se encargaron de complementar el trabajo diplomático que requería la celebración de las entrevistas entre Franco y las autoridades extranjeras.

Sin lugar a dudas, la relación de huéspedes obedeció a las simpatías personales y a las afinidades del anfitrión. En consecuencia con ello, la coincidencia con las figuras invitadas fue indiscutible, abarcando desde militares de alta graduación a monarcas autoritarios, líderes dictatoriales o muy conservadores. Les unía el vocabulario, sus fines, sus formas, sus métodos represivos y de control social. En este marco, los dirigentes de Argentina, Perú, República Dominicana, Panamá, Venezuela, Brasil, Paraguay y Nicaragua se pasearon en repetidas ocasiones por Madrid y otras ciudades españolas, en las que pudieron comprobar la evolución económica y social del franquismo, realizándose la mayor parte de estas giras en las décadas de 1950 y 1960. Pero hubo también quien faltó a la cita con la antigua metrópoli, como los dirigentes civiles de perfil liberal y las autoridades mexicanas, país con el que España no mantuvo relaciones diplomáticas oficiales hasta después de la muerte del dictador. La ausencia de contactos personales no impidió, sin embargo, que ciertos dirigentes enviaran mensajes de reconocimiento a Franco. Haití, Colombia, Chile o Ecuador, entre otros, le condecoraron con las más altas distinciones de sus estados en prueba de la admiración que le profesaban y como gesto de amistad. ${ }^{9}$ En realidad, la antigua metrópoli les ofrecía poco: cultura - contaban ya con una representación a través de los republicanos exiliados instalados en casi todos los países de la región-; pasado imperial —anticuado y sin réditos claros para el presente- y votos en Naciones Unidas a partir

9 Las condecoraciones fueron: por parte de Haití, en febrero de 1951, concesión de la Gran Cruz, placa oro de la Condecoración Honneur et Mérite; en la misma fecha el gobierno de Colombia le condecoró con la Gran Cruz Extraordinaria de la Orden de Boyacá; desde Ecuador se remitió en julio de 1953 la Gran Cruz Extraordinaria de la Orden del Mérito del Ecuador, y en enero de 1956 en su más alto grado, el Gran Collar de la Orden Nacional "Al Mérito". Procedente de Chile en junio 1955, Collar de la Orden al Mérito Bernardo O'Higgins. Asimismo en agosto de 1956 tuvo lugar la imposición del Gran Collar de la Orden de Pedro de Valdivia. Archivo del Ministerio de Asuntos Exteriores de Madrid (en adelante AMAE), leg. R-6981.21, R- 6953.96, R6953.151 y R-6953.108 y 109, respectivamente. 
de 1955. El atractivo fundamental de España era el pacto firmado con Estados Unidos en 1953 que le dotó en un principio de cierto aire prometedor, aunque pronto fueron conscientes de que Madrid no realizaría inversiones significativas y que no podía erigirse en líder de ningún bloque.

Tampoco las antiguas colonias podían ofrecer mucho a la España autárquica y antidemocrática. Tenían un escaso peso internacional, en su mayoría estaban supeditadas a la acción política y económica norteamericana, y se hallaban en un proceso lento de desarrollo con altos índices de pobreza y desempleo. Además, en los años cincuenta y sesenta muchas habían registrado movimientos revolucionarios o eran víctimas de una gran conflictividad. Se trataba, en consecuencia, de una zona con una importante inestabilidad hacia la cual la España franquista tenía cierta prevención, aunque nunca se expresara públicamente. La idea del contagio revolucionario y de la introducción subterfugia del comunismo estuvo presente en las conversaciones confidenciales de las autoridades franquistas, a menudo reacias a concluir tratados con ciertos países susceptibles de caer en las veleidades del socialismo revolucionario.

Las visitas de estos altos representantes respondían a diferentes motivaciones, que podemos tipificar en torno a cuestiones de afinidades ideológicas, de beneficios económicos o de intereses políticos. Incluso hubo visitas, como las de algunos argentinos, que obedecían a una promoción política personal. A veces un encuentro perseguía varios fines. Todas ellas vinieron precedidas de un trabajo intenso de los gabinetes ministeriales de Exteriores, de Economía o de Cultura cuyos funcionarios desempeñaron un papel crucial en todo el proceso.

Entre los considerados como "afinidad ideológica" figuran los de Argentina, República Dominicana, Nicaragua y Paraguay. Si bien, hemos de destacar que los viajes de los argentinos Alejandro Agustín Lanusse (febrero de 1973) y Héctor Cámpora (junio de 1973) no fueron emprendidos con la intención prioritaria de despachar con Franco, sino con el propósito de captar el apoyo de Juan Domingo Perón para las elecciones. ${ }^{10}$ Los viajes relacionados con las necesidades informa-

${ }^{10}$ Casa Civil de S. E. el jefe del Estado y Glmo. de los Ejércitos, Protocolo, Visita a España de personalidades extranjeras, 1973, Archivo Palacio Real (en adelante APR). Sobre las relaciones 
tivas directas, primaron en las estancias de los representantes de Panamá (abril de 1953), El Salvador y Perú (ambos en junio de 1953), atraídos por el inicio de las relaciones bilaterales hispano-norteamericanas. ${ }^{11}$ Como hemos dicho anteriormente, algunos viajes aunaron distintos intereses y fueron aprovechados para conocer los avances sociales de la España franquista, como fue el caso de la esposa del presidente de Perú, María Delgado de Odría (junio de 1953).

Finalmente, los temas económicos tuvieron prioridad en las conversaciones con los dirigentes de Brasil (enero de 1956), Venezuela (octubre de 1956) y Costa Rica (noviembre de 1956), aunque este país fue una excepción para El Pardo. Esta cita fue una táctica propagandística del gobierno franquista, quien quiso aparecer con una actitud tolerante y de amplia generosidad con la aprobación de la visita oficial de un jefe de Estado de origen español que deseaba volver a la madre patria y que, a pesar de sus diferencias políticas, era aceptado por Franco. La entrevista con Arturo Frondizi de Argentina (julio de 1960) cabría incluirla, igualmente, en este grupo, cuyo eje giraba en torno al establecimiento de relaciones económicas.

Podemos establecer, además, un primer grupo de estados con los que existían lazos estrechos por razones de analogía política, que integraría a Argentina, República Dominicana, Nicaragua y Paraguay, y un segundo grupo reuniría a Venezuela, Perú, El Salvador y Brasil, con quienes se entablaron meras relaciones cordiales. En consecuencia, la denominada "Comunidad Hispánica de Naciones" quedaba circunscrita a un colectivo reducido de territorios con regímenes dictatoriales, militaristas o de democracias sesgadas. En todas ellas, el fuerte control social, económico, la represión de la oposición y la permanente presencia del ejército, forman parte de los elementos comunes que las definen.

Franco-Perón hemos de destacar, entre otros, los trabajos de Raanan Rein, The Franco-Peron Alliance. Relations between Spain and Argentina, 1946-1955, Pittsburgh-Londres, University of Pittsburgh Press, 1993. Marisa González de Oleaga, "La alianza Franco-Perón: una aproximación crítica desde la perspectiva de la dependencia, 1946-1951", en Hispania, vol. 48, núm. 169, 1988, pp. 625-690.

${ }^{11}$ Casa Civil de S. E. el jefe del Estado y Glmo. de los Ejércitos, Protocolo, Visita a España de personalidades extranjeras, APR, 1953. 
En cuanto a la distribución cronológica de las visitas, a excepción de la realizada por Eva Perón en 1947, el primer año del aislamiento internacional de España, el resto estuvieron polarizadas en torno a la coyuntura de 1953 - firma de Pactos con Estados Unidos-, y 1956 - diversas crisis internacionales-. Es decir, básicamente coincidieron con la década de mayor actividad internacional de los gobiernos franquistas, la de los años cincuenta. No obstante, en el tardofranquismo se celebraron algunas recepciones relevantes, como la de Nicaragua (mayo de 1966) y Paraguay (julio de 1973).

El excelente trato concedido a los séquitos y a las diplomacias de los países que fueron recibidos en Madrid, se completó con un plan turístico diseñado con una cuidada selección de las ciudades, monumentos y museos en función de su procedencia o la explotación de los recursos típicos del folclore ya fueran los toros, los espectáculos flamencos o las cacerías. Los programas de estancia gozaban de tanta importancia para el éxito de la misión extranjera como los contenidos y el desenlace de las reuniones. El plan incluía, para todos los invitados, independientemente de su lugar de origen, el obligado cumplido de El Escorial, el Alcázar de Toledo y el Valle de los Caídos, monumentos expresivos de la grandeza imperial, el heroísmo y sacrificio nacionalista en la Guerra Civil y la exaltación del dictador. A los líderes iberoamericanos se les reservaban excursiones a algunas ciudades castellanas -Segovia, Ávila — o a las más industrializadas como Barcelona, Zaragoza o Bilbao, aunque a veces repetían el mismo periplo andalusí de los dirigentes árabes, es decir, Granada, Sevilla y Córdoba. Generalmente se completaban con inspecciones a organismos ilustrativos de la política social, como centros de formación profesional, escuelas de artesanía o centros relacionados con otro tipo de cobertura social como orfanatos, escuelas, hospitales o comedores. Muchos de estos países se hallaban, al igual que España, en vías de desarrollo y estaban interesados en comprobar el funcionamiento del modelo social franquista. A esta operación propagandística se añadían las visitas al museo de El Prado y la asistencia a actos culturales que preparaba el Instituto 
de Cultura Hispánica, teniendo en cuenta que la lengua y la historia común eran las artífices del enlace hispanístico. ${ }^{12}$

Además de los banquetes con las élites políticas y económicas, los invitados compartían grandes recepciones con miembros destacados de los grupos sociales que apoyaban al régimen, es decir, representantes de la aristocracia, la Iglesia, la universidad, los militares, los falangistas y a partir de los años sesenta con los tecnócratas del Opus Dei. La grandilocuencia de los discursos en las ceremonias oficiales rayaba en la fatuidad, especialmente en los pronunciados ante los árabes y los latinoamericanos. Expresiones como "el genio de la raza", "el quijotismo hispánico", "la solidaridad con el alma de la España eterna" o la "hispanidad erguida frente al materialismo sin alma", eran realmente vacuas pero de un gran impacto emocional, especialmente ante los líderes afines. Los huéspedes eran homenajeados con condecoraciones de alta graduación mientras que Franco recibía medallas, cruces y distinciones en prueba del reconocimiento de su papel en la lucha contra el comunismo, en esa peculiar interpretación de los acontecimientos que divulgó el fanquismo.

A continuación analizaremos las visitas de Eva Perón, Rafael Leónidas Trujillo y Alfredo Stroessner. Hemos seleccionado estos tres casos como ejemplos de encuentros realizados en coyunturas políticas especiales: la primera dama argentina viajó a Madrid en 1947, en plena crisis de subsistencias y aislamiento internacional; Rafael L. Trujillo lo hizo en 1954, el año central entre la firma de los acuerdos con Estados Unidos y el ingreso de España en Naciones Unidas; mientras que A. Stroessner visitó a Franco en 1973, el año de la crisis económica provocada por la guerra del Yom Kippur, uno de los conflictos árabe-israelíes de mayor impacto mundial. Estos dirigentes eran los mejores aliados a quien recurrir en caso de necesidad: Argentina y la República Dominicana no se habían sumado a las sanciones impuestas por Naciones Unidas a España mien-

12 Ingrid Schultze, "Franco, propagandista internacional", en Juan Antonio García Galindo y otros [eds.], La comunicación social durante el franquismo, Málaga, Diputación Provincial y Asociación de Historiadores de la Comunicación, 2002, pp. 243-259. 
tras que Paraguay, desde la llegada al poder de Stroessner, había manifestado una gran admiración hacia Franco y su política.

\section{EVITA Perón en España. La eXPlotación POLÍtTCA Y PROPAGANDÍSTICA DE UN MITO}

Desde el inicio del mandato de Juan Domingo Perón las manifestaciones de simpatía hacia el gobierno español fueron claras. Recién instalado en la presidencia, confirió al general Franco el Collar de la Orden del Libertador San Martín "para robustecer y afianzar la buena y tradicional amistad existente entre la República Argentina y la nación española, enalteciendo y acrecentando los vínculos espirituales, culturales y económicos que la rigen". ${ }^{13}$ Esta actitud fue recíproca puesto que España, inmersa en una etapa de profunda crisis económica y política, no contaba con muchas opciones de alianzas y necesitaba a Argentina como proveedor de trigo.

La afinidad ideológica entre los gobernantes y los mutuos intereses comerciales impulsaron un entendimiento recíproco. Argentina funcionó como un salvavidas para solucionar la cuestión alimenticia a corto plazo mediante la firma del Protocolo Franco-Perón, en virtud del cual España recibía un crédito para salir del estrecho callejón en el que se hallaba gracias a las resoluciones de Naciones Unidas. ${ }^{14}$ Durante el periodo 1946-1948, el Protocolo proporcionó ayuda diplomática y política, la defensa del gobierno franquista en los foros internacionales, las acciones persuasivas ante otros ejecutivos latinoamericanos con el fin de mejorar las relaciones con Madrid, y visitas de representaciones políticas y económicas argentinas que culminaron con la llegada de la esposa del presidente en junio de $1947 .{ }^{15}$ Estas actividades tenían una importancia ex-

13 Collar Orden del Libertador San Martín, Argentina, AmAe, leg. R-6953.4, 1946.

${ }^{14}$ Resumen de los puntos que se tratarán en las negociaciones con Argentina, Fundación Nacional Francisco Franco (en adelante FNFF), doc. 13108, 1946.

${ }^{15}$ Entre algunos de los monográficos dedicados a su estudio figuran: Beatriz J. Figallo, El Protocolo Franco-Perón. Relaciones hispano-argentinas, 1942-1952, Buenos Aires, Ed. Corregi- 
traordinaria, puesto que la ayuda económica procedente del Plan Marshall no llegó a España y no había ninguna otra nación dispuesta a financiar al denostado ejecutivo hispánico.

En este marco, el viaje de la primera dama constituyó el punto culminante de la acción del Ministerio de Asuntos Exteriores. Evita significó el símbolo más visible del pacto Madrid-Buenos Aires, a pesar de que su apariencia y orígenes constituían un cierto desafío a los valores y principios del régimen. Representaba el sueño del cese del hambre, el triunfo popular y la ayuda del antiguo imperio a su metrópoli. Su resplandeciente aspecto y los agasajos preparados en su honor, se transformaron en un espectáculo de gran magnitud, un instrumento de propaganda de primer nivel y una oportunidad única para desviar la atención de las masas de los problemas cotidianos como las restricciones impuestas con la cartilla de racionamiento, las visitas a los presos políticos en las cárceles, el difícil contacto con el familiar exiliado, las compras furtivas en el mercado negro o la escasez general de materias primas.

El 9 de junio, Franco recibió en el aeropuerto de Barajas a la primera dama argentina con honores de jefe de Estado, según ella misma había indicado. El Caudillo aceptó sus exigencias y toleró los excesos protocolarios puesto que Argentina estaba desafiando la condena lanzada contra España en Naciones Unidas. Las altas esferas del gobierno acudieron a recibirla también y al final de la ceremonia de bienvenida una larga hilera de automóviles oficiales la condujo a través de las principales calles de Madrid, donde el pueblo la vitoreó calurosamente. ${ }^{16}$ Las portadas de la prensa se hicieron eco de esas primeras fotografías de su llegada, el recibimiento y la acogida multitudinaria que se le preparó. ${ }^{17}$ Eva compareció ante el numeroso público congregado por Falange y las orga-

dor/Pontificia Universidad Católica, 1992. Raanan Rein, La salvación de una dictadura. Alianza Franco-Perón, 1946-1955, Madrid, CSIC, 1995. Marisa González de Oleaga, Las relaciones hispano-argentinas, 1939-1946. Identidad, ideología y crisis, Madrid, Universidad Complutense, 1991. De esta misma autora, El doble juego de la Hispanidad ..., ya citado.

${ }^{16}$ Casa Civil de S. E. el jefe de Estado y Glmo. de los Ejércitos, Protocolo, Visita a España de personalidades extranjeras. Palacio de Oriente, APR, leg. 1, años 1942, 1947 y 1949.

17 Véase, entre otros, las portadas de La Vanguardia Española y ABC, 10 de junio, 1947. 
nizaciones juveniles para ser homenajeada en el balcón de la Plaza de Oriente, desde donde se oyó una retransmisión radiofónica de Juan Domingo Perón. En el palacio de El Pardo la esperaban los ministros con sus esposas, el Cardenal Primado, el embajador argentino, el presidente del Tribunal Supremo, almirantes, generales y la aristocracia española, todos embelesados ante su figura. Es decir, un conjunto muy nutrido de los grupos sociales más representativos del régimen franquista, que venían a conocer y agasajar a esta especie de heroína que les servía como distracción pasajera de su endogámica forma de vida en el Madrid de posguerra.

Al día siguiente de su llegada, Franco le impuso la Gran Cruz de Isabel la Católica, la mayor de las condecoraciones españolas. Comercios, oficinas y fábricas cerraron durante cuatro horas, el ministro de Educación proclamó un día de asueto en las escuelas, y los sindicatos verticales incitaron a los trabajadores a concurrir al acto principal a fin de que pudieran participar en una demostración de masas en apoyo de Argentina y de Franco. En la ceremonia celebrada en El Palacio Real, éste pronunció un discurso que versaba sobre la Hispanidad y el concepto de España como madre y creadora de naciones. No olvidó los elogios a los principios del peronismo, a los que comparó con la grandeza del pasado español. Evita retribuyó con alabanzas y, sobre todo, hizo referencias propagandísticas a la obra de su marido. Después de la ceremonia, transmitida por altavoces a la multitud que esperaba fuera, salió al balcón del palacio al lado de Franco donde la muchedumbre aplaudía, y donde tuvo lugar una anécdota en la que se vio involucrado un puñado de falangistas que saludaron con el ademán fascista perjudicando notablemente la imagen de Perón. ${ }^{18}$

El itinerario seguido durante los quince días de estancia, incluía un gran número de ciudades de Castilla, Andalucía, Galicia y Cataluña, en las que le ofrecieron innumerables recepciones y agasajos. Evita tuvo un nutrido programa de

${ }^{18}$ En el momento de salir al balcón un puñado de falangistas que se hallaban en el centro de la plaza, levantó la mano haciendo el conocido saludo fascista. Muchos otros se les unieron en este gesto que había sido prohibido. Evita y Franco devolvieron el saludo, aunque no está claro si ella levantó la mano saludando. El caso es que la prensa mundial dijo que había hecho el saludo fascista, lo cual perjudicó la imagen de Perón a quien se le recordó su pasado al lado de los nazis. 
actividades sociales con representantes de diferentes sectores profesionales. Quiso ver bloques de viviendas, escuelas de capacitación profesional, mercados de artesanía y hospitales, pronunciando discursos sobre el progreso social, el bienestar de los trabajadores y la necesidad de renovar el pensamiento del siglo XIX. En todas partes las multitudes la saludaron y la percibieron como la representante de un país rico, símbolo de prosperidad y esperanza, una posible fuente de crédito y de importación de alimentos, la tierra de posibilidades ilimitadas sólo superada por Estados Unidos.

El impacto en la sociedad española de la época fue profundo debido a su juventud, estética y actitud: pidió que se libertaran a dos antifranquistas que habían puesto una carga de explosivos en la embajada argentina de Madrid tres meses antes, y se ofreció para ser madrina de todos los niños nacidos durante su visita. Su estancia resultó ser un vehículo perfecto para la propaganda del régimen puesto que Franco se benefició de la popularidad que la envolvía, factor que le ayudó a aparecer con un perfil de hombre del pueblo en unos días coincidentes con la celebración del referéndum sobre la Ley de Sucesión a la Jefatura del Estado. Perón envió barcos con trigo y maíz a Barcelona como gesto de agradecimiento y abundancia.

La actitud hospitalaria del pueblo, las muestras de deferencia del Caudillo, la tolerancia respecto a la falta de cumplimiento del protocolo y hacia el estilo de éste, volcaron decididamente la simpatía de Eva hacia España. Cuando algunos días después estuvo con el Papa Pío XII, aprovechó para elogiar la magnífica obra de recatolización que estaba realizando el franquismo, y le atribuyó el gran mérito de ser el único defensor de la Iglesia en Europa. A la vuelta del periplo, Perón parecía verdaderamente emocionado por la narración de su esposa y no dejaba pasar ocasión sin alabar a su amigo. ${ }^{19}$ La visita había sido muy cara, pero Franco quedó definitivamente vinculado a Argentina y ésta se empeñó en crearle un ambiente favorable en Naciones Unidas.

19 Perón envió a Franco como presente tres caballos de raza, dos caballos trotadores para su hija Carmencita, dos vacas holando-argentinas y un toro joven. Carta manuscrita de Perón a Franco, FNFF, doc. 2539, 17 de diciembre, 1947. 
Eva Duarte, sin embargo, no vino exclusivamente a España como el régimen hubiera deseado. Madrid fue una escala más en el viaje que realizó por Europa y en la que pisó el Vaticano, París, Roma, Lisboa y Berna. En estos países no le prodigaron el recibimiento que Franco le ofreció, incluso en algunos hubo abucheos. La prensa francesa aludió a ella en términos hostiles y en Roma se convocaron manifestaciones ante la embajada argentina como expresión de protesta ante su presencia. En Gran Bretaña la visita se suspendió al advertir al protocolo argentino de que no se le concedería carácter oficial, además del riesgo de la existencia de problemas de orden público como consecuencia de su encuentro con el dictador español.

La visita de Eva y la propaganda del Protocolo Franco-Perón sirvieron para contrarrestar ante la opinión pública la desilusión que produjo el hecho de que el Plan Marshall no llegara a España debido al carácter antidemocrático de su gobierno. La luna de miel hispano-argentina, sin embargo, sólo duró hasta 1949, cuando Perón suspendió la aplicación del Convenio y los embarques de cereales hacia la Península, aunque este hecho no significó que la amistad entre ambos se rompiera. ${ }^{20}$ No se concederían nuevos créditos ni se seguiría aplicando el Protocolo mientras no mejoraran las condiciones económicas de ambos países, especialmente la de Argentina, que alegaba una situación desastrosa en su acopio de divisas. Para Madrid la ruptura significó una catástrofe, puesto que el déficit alimenticio sin el trigo argentino podía alcanzar niveles alarmantes. El gobierno, en consecuencia, se vio obligado a movilizar sus reservas y a diversificar las compras en otros mercados, pero las relaciones continuaron siendo estrechas como el régimen mostró con la acogida de Perón como exiliado de lujo desde finales de 1955 hasta su retorno a Argentina en 1973.

${ }^{20}$ Dictamen en el que se exponen los condicionantes sobre el Protocolo, FNFF, doc. 12686, 23 de febrero, 1949. 
LA VISIBILIDAD DE LAS ALIANZAS ENTRE DICTADORES:

RaFAEl LeÓnidas Trujillo EN MADRID

Rafael Leónidas Trujillo protagonizó una de las dictaduras más longevas del continente iberoamericano (1930-1961). Cuando Franco triunfó en España en abril de 1939, Trujillo contaba con una larga experiencia política, caracterizada por la práctica de la intriga y la usurpación en provecho propio y de su clan. El Jefe, nombre con el que se le conocía internamente, fue uno de los dictadores que eliminó sistemáticamente a la oposición interna, desarrolló mecanismos de represión de gran dureza y eficacia y utilizó al ejército como el instrumento principal para su mantenimiento en el poder, es decir, un conjunto de procedimientos convergentes con el estilo del gobierno franquista. ${ }^{21}$ Sobre las apologías de las que se rodeó, basta sólo mencionar los títulos auto-otorgados entre los que figuran, Benefactor de la Patria (1933), El más grande de los jefes de Estado dominicanos (1938) o Padre de la Patria Nueva (1954).

La dominicanidad en Trujillo y la españolidad en Franco, el catolicismo, la hispanidad y el anticomunismo, fueron elementos genéricos a sus regímenes, además del legado de transgresión de los derechos humanos comunes también a ambas políticas. Alonso Vázquez ha señalado que la colaboración se materializó en la Guerra Civil, pero, sobre todo, en el apoyo al ingreso de España en Naciones Unidas y en el respaldo permanente a las propuestas del gobierno franquista. En la votación que tuvo lugar en diciembre de 1946 sobre la retirada de embajadores, los representantes dominicanos votaron en contra y empren-

${ }^{21}$ Son numerosos los libros publicados sobre R. L. Trujillo, entre otros: Jesús de Galíndez, La era de Trujillo. Un estudio casuístico de dictadura hispanoamericana, Santiago de Chile, Editorial del Pacífico, 1956. José Almoina, Una satrapía en el Caribe. Historia puntual de la mala vida del déspota Rafael Leónidas Trujillo, Santo Domingo, Cole, 1999. Francisco Javier Alonso Vázquez, La alianza de dos Generalísimos. Relaciones diplomáticas Franco-Trujillo, Madrid, Fundación García Arévalo, 2006. Del mismo autor, "La relación Franco-Trujillo", en Cuadernos Hispanoamericanos, núms. 613-614, Madrid, 2001. Ángel Lockward y Francisco Javier Alonso Vázquez, Informes secretos de Franco a Trujillo, Santo Domingo, Editora Universitaria-UASD, 2007. Domingo Lilón, "Las relaciones dominico-hispanas durante Trujillo y Franco, 1936-1961", en Toni Berta [coord.], Az Identitás régi és új Koordinátái. Tanulmányok Anderle Ádám 65 születésnapjára, Hungría, Universidad de Szeged, 2008. 
dieron una acción contraria a la mayoría, que consistió en elevar a rango de embajada permanente lo que con anterioridad era sólo una legación diplomática. España respondió el 16 de abril de 1948 con el nombramiento del primer jefe de misión diplomática española, que se acreditó con el rango de embajador extraordinario y plenipotenciario, Manuel Aznar Zubigaray, quien orientó su discurso a ensalzar la historia y la cultura española, no sólo en la Isla, sino en todo el subcontinente americano, es decir, el montaje de una estrategia basada en la construcción de una cultura común de siglos de antigüedad.

En junio de 1948, Franco había recibido la Gran Cruz con Placa de Oro de la Orden de Cristóbal Colón como gesto de respaldo a su gestión a pesar de la condena internacional a la que estaba sometida. Los homenajes se confirmaron en dos ocasiones más con la imposición de las máximas condecoraciones que fueron compensadas con otras a Trujillo, como homólogos reconocimientos a su gestión al frente de la República Dominicana. En suma, correspondencias públicas de la identificación entre los dos dictadores elevados a la máxima categoría institucional. ${ }^{22}$

La misión diplomática del embajador Manuel Valdés Larrañaga, iniciada en 1951, fue la encargada de preparar el viaje que Trujillo realizó a España. En julio de 1953 había tenido lugar la visita de su hija María de los Ángeles, disfrutando de unas jornadas de ocio y turismo, aunque no exentas de cierta exploración política ante la futura llegada de su padre. ${ }^{23} \mathrm{Al}$ año siguiente, Trujillo llegó a Madrid el 2 de junio donde Franco y todo el gobierno le esperaban en la Estación del Norte. En estos momentos su hermano Héctor ostentaba la presidencia de la República siendo éste el primer viaje oficial fuera de sus fronteras. ${ }^{24}$

22 Gran Cruz República Dominicana, AmaE, leg. R- 6953.132, 1948 y 1954. En 1950 fue la concesión de la Gran Cruz con Placa de Oro de la Orden del Mérito Juan Pablo Duarte y la de la Gran Cruz de la Orden de Trujillo con Placa de Oro, máximo grado reservado para jefes de Estado, otorgada personalmente por Trujillo a Franco durante su estancia en España en 1954. Franco concedió también grandes cruces de la Orden de Isabel la Católica a secretarios de Estado y otras autoridades dominicanas. Igualmente, regaló a Trujillo un caballo valorado en 45000 ptas.

${ }^{23}$ Casa Civil de S. E. el jefe de Estado y Glmo. de los Ejércitos, Protocolo, Visita a España de personalidades extranjeras, Palacio de Oriente, APr, años 1953, 1954, 1955.

${ }^{24}$ Viaje a España de Trujillo del 2 al 14 de junio, AMAe, leg. R- 5847.9, 1954. 
El recibimiento y la estancia de Trujillo y su familia fueron apoteósicos. El alcalde de Madrid declaró fiesta escolar el día de la llegada, y se engalanó la ciudad para una recepción espectacular. Los dos dictadores se sentían henchidos ante la identidad ideológica que les unía, confraternizados no sólo en el pasado imperial, sino en el presente político que se presentaba, desde su punto de vista, esperanzador y exitoso ante la firma de los Pactos con Estados Unidos en 1953 y la próxima incorporación de España a Naciones Unidas. El periódico La Vanguardia Española del 3 de junio de 1954 titulaba su portada "Un paladín del anticomunismo" y ofrecía una imagen de un monumento de Trujillo a caballo, mientras que $A B C$ publicaba una foto de cuerpo entero, y cubría la noticia con un amplio despliegue en su interior. Franco parecía delirar ante la llegada de Trujillo, a quien prodigó frases gloriosas de admiración y agradecimiento. En el discurso de bienvenida habló de la siguiente manera:

Ninguna satisfacción más grande e íntima para una familia que la vuelta al hogar de algunos de sus hijos alejados, así sucede hoy en nuestra nación al recibir la visita del Generalísimo Trujillo, Benefactor de su Patria, que durante tantos años viene siendo el Jefe indiscutible de la Nación Dominicana, la primogénita de nuestras hijas de América, y que si recibió el nombre de Española en su bautismo, demostró en el transcurso de su historia su gran amor y adhesión al viejo tronco que le dio vida con actos divinos que los españoles jamás olvidaremos. [... Es Este imperio de la fe que en vuestra Nación tanto cuidáis, es una nueva razón y poderosa razón de que vuestra presencia entre nosotros sea todavía más querida y apreciada, pues no solo [sic] sois el auténtico Jefe a quien tanto debe la prosperidad de vuestra Patria, ni el gran amigo de los días difíciles, ni el gallardo confesor de sus sentimientos hispanos, sino el gran defensor de aquella manera de ser y de sentir, y de aquella fe que un día llevaron a aquellas tierras nuestros capitanes y misiones, y si esto fuera poco, sois también, Excelentísimo Señor, el paladín del anticomunismo en el mar de las Antillas. ${ }^{25}$

${ }^{25}$ El ministro de Asuntos Exteriores, Alberto Martín Artajo envió el discurso al encargado de Negocios de Ciudad Trujillo para que lo difundiera por la prensa dominicana y caribeña, AMAE, leg. R. 5847.9, 1954. 
Las jornadas fueron organizadas conforme a una planificación exhaustiva del tiempo para que El Jefe y su familia pudieran conocer las principales urbes españolas -Madrid, Barcelona-, pequeñas ciudades próximas a la capital -Ávila y Toledo-y municipios relevantes para el imaginario franquista -El Escorial- Hubo también cultura - museo de El Prado-, ocio y deportes del gusto de Franco - caza, corridas de toros y espectáculos de danza española- y demostraciones militares. Prodigaron los ágapes y banquetes con militares y civiles, actos sociales multitudinarios preparados para la exaltación de ambos líderes, escenarios panegíricos de sus hazañas pasadas y presentes en los que abundaron discursos sobre los paralelismos entre ambos generalísimos, como el pronunciado por Trujillo en una cena en el Palacio Real de Madrid:

Nuestra política se halla inspirada en los mismos ideales que presiden la política de la Madre Patria. Estamos realizando, con energía inquebrantable, un programa de reivindicación y engrandecimiento nacionales, semejante al que la España tradicionalista, la España eterna, está llevando a cabo en un escenario naturalmente más extenso [...]. La lucha que el Generalísimo Franco, campeón de la hispanidad y paladín del espíritu cristiano, encabezó aquí contra las fuerzas del ateísmo contemporáneo, cuando todavía el destino del hombre no había empezado a decidirse en los campos de la segunda guerra mundial, es la misma lucha que hoy están librando en un escenario más vasto todos los pueblos del mundo occidental. ${ }^{26}$

La despedida fue igualmente entusiasta. Los dos se colmaron de elogios, de recuerdos del pasado y de promesas de futuro, y a partir de este viaje intensificó más sus ideales, a saber, el anticomunismo y el nacionalismo, especialmente el primero de los mencionados, muy acentuado después de las conversaciones con Franco.

La visita del general Rafael Leónidas Trujillo y esposa tuvo gran eco en los medios de comunicación, en los que se reprodujeron con profusión imágenes en actitud de una intensa compenetración. Los mensajes difundidos en España

${ }^{26}$ Rafael Leónidas Trujillo, Discursos, mensajes y proclamas, Madrid, Ediciones Acies, 1957, pp. 64-66. 
y en la República Dominicana, confeccionados con el matiz de la censura y de las consignas oficiales, dieron como resultado una cobertura fuera de toda proporción real a este pretendido acercamiento. Ciertamente, la ostentación de una estrecha amistad entre los dictadores no producía beneficios especiales más allá de la continuidad del apoyo en Naciones Unidas, el acuerdo de colaboración de las fuerzas de seguridad españolas con las dominicanas, y el cierre de filas con un aliado en el Caribe que a su vez era aliado de Estados Unidos. El encuentro se producía, sin embargo, en un momento oportuno, coincidente con la compleja situación creada en Guatemala por el coronel Jacobo Arbenz, quien había legalizado el Partido Comunista Laborista guatemalteco y se disponía a poner en marcha una reforma agraria de amplias dimensiones. Las políticas de Arbenz se percibieron como una amenaza comunista, concepción que sirvió al ejército para unirse al consorcio de la cia y la United Fruit Company en sus propósitos de derrocarle. En esta coyuntura, Estados Unidos vio con buenos ojos las declaraciones contundentes de aliados anticomunistas, que previsiblemente contribuirían a desestimar otros intentos de reforma en la región centroamericana, y comprobaron con Franco la existencia de un dócil intermediario.

\section{PROPAGANDA Y VIEJAS DICTADURAS:}

\section{Alfredo StroessNer y Franco}

El general Alfredo Stroessner fue uno de los dictadores latinoamericanos que permaneció en el poder durante largas décadas (1954-1989) apoyado en la oligarquía económica nacional, el ejército y Estados Unidos. En 1954 dio un golpe de Estado que derribó al anterior presidente, implantó una dictadura militarista, suspendió la Constitución, ilegalizó a los partidos políticos y suprimió las libertades democráticas, provocando el exilio de miles de personas.

El presidente paraguayo era un gran admirador de Hitler y Franco, favorable a la presencia de una Iglesia católica ultraconservadora, partidario de la autarquía, ferviente anticomunista y buen anfitrión de nazis y de dictadores, como Anastasio Somoza Debayle. Stroessner se miraba en el espejo de Franco para conducir su país y admiraba de él su anticomunismo exacerbado y ese concepto 
nacionalista que ensalzaba la patria, el heroísmo de sus hombres, el paternalismo que engaña, propio de los dictadores. ${ }^{27}$

El general Alfredo Stroessner y su esposa estuvieron en Madrid en julio de 1973. Su visita generó una amplia cobertura propagandística en los medios de comunicación, donde se volcó una información en términos extremadamente laudatorios sobre los aspectos que conformaban la realidad hispana y paraguaya, así como sobre la personalidad de sus respectivos líderes, entre quienes se establecían comparaciones en sus similares orígenes, su obra político-social y su misión como dirigentes destinados a salvar a sus patrias. ${ }^{28} \mathrm{El}$ alcalde de Madrid le entregaba las llaves de la villa con las siguientes palabras:

Señor presidente: Hoy es un día de fiesta para Madrid. Y no sólo porque recibimos la visita del jefe del Estado de un país unido al nuestro por vínculos históricos de profunda raigambre, sino porque sabemos que sois un buen amigo de España [...]. Sois, señor presidente, la máxima representación de un pueblo que coloca el heroísmo por encima de todas sus cualidades y virtudes [...]. Vuestro pueblo luchó con admirable arrojo contra fuerzas muy superiores en número hasta casi el exterminio. Pero su gallardía no fue inútil, pues, habéis mantenido intacto el tesoro de vuestra independencia nacional. Y el pueblo de Madrid, que también supo luchar y morir por la independencia de España, puede comprender muy bien. Porque nos une a paraguayos y españoles la suprema hermandad del patriotismo heroico. ${ }^{29}$

El dictador paraguayo fue agasajado con exhibiciones populares de cantos y bailes en una España desarrollada económicamente, y con una oposición interna poco dispuesta a considerar recepciones a dictadores. Stroessner no se conformó con la obligada visita al Valle de los Caídos y El Escorial, sino que rin-

27 A principios de 1954, Franco había recibido en El Pardo, a través del embajador del Paraguay en Madrid, la Orden Nacional del Mérito en el grado de Cruz Extraordinaria bordada en oro, para testimoniar el reconocimiento y la simpatía que profesaban a la madre Patria y al Caudillo. Gran Cruz de la Orden Nacional del Mérito de Paraguay, Amae, leg. R-6981. 110, 1953. Una breve reseña crítica de su figura en la revista Triunfo, núm. 543, 24 de febrero, 1973, p. 13.

${ }^{28}$ Aclamaciones especialmente exageradas fueron las escritas por Ernesto Giménez Caballero en el periódico El Alcázar, de 16 de julio, 1973, en un artículo titulado "Stroessner y Franco".

${ }^{29}$ La Vanguardia Española, p. 4, 17 de julio, 1973. 
dió homenaje ante la tumba de José Antonio en un estilo fascista poco acorde con el mundo que le contemplaba. Durante su estancia asistió a varias reuniones con directivos del Banco Exterior de España, un reducido número de jefes de misiones diplomáticas y con el príncipe Juan Carlos. ${ }^{30}$

Las relaciones políticas bilaterales eran excelentes pero poco equilibradas con lo económico, bastante escasas en los intercambios, cuyas cifras apenas alcanzaban 1\% del que se realizaba con Latinoamérica, a pesar de que se habían firmado entre ambas naciones unos 20 convenios. En 1966 se acordó el Acta de Asunción sobre cooperación técnica y económica, en la que se preveía participar en el programa paraguayo que incluía acelerar los procesos de industrialización de materias primas y de transformación de productos para el consumo interno y la exportación. El Acta seguía en vigor pero no se habían efectuado los intercambios previstos.

En la visita de 1973 hubo diversas reuniones con el objetivo de profundizar en la colaboración económica, concretamente la inversión española en la construcción de infraestructuras, la firma de algunos acuerdos sobre créditos bancarios, la cooperación técnica y el turismo. Las relaciones económicas, pues, figuraban entre los objetivos prioritarios de la visita, de ahí que en su séquito se hallaran el ministro de Obras Públicas y Comunicaciones, el de Hacienda, el presidente del Banco Central y otras personalidades del mundo financiero.

El viernes 20 de julio en el Palacio de la Moncloa, Stroessner y Franco firmaron un documento llamado Declaración de la Moncloa, en el que reiteraban su adhesión a los principios fundamentales que regían las relaciones entre las naciones, coincidían en la necesidad de fortalecer Naciones Unidas, como un instrumento al servicio de la paz y de la seguridad internacional, incluían en este concepto la seguridad económica y reconocían la necesidad de reformar los sistemas comerciales y financieros. Por último, hicieron públicas las buenas relaciones entre ambos estados, la eficacia de la cooperación bilateral y su propósito de ampliar e intensificar las relaciones culturales, la colaboración técnica y científica. ${ }^{31}$

${ }^{30}$ Casa Civil de S. E. el jefe de Estado y Glmo. de los Ejércitos, Protocolo, Visita a España de personalidades extranjeras, Palacio de Oriente, APR, 1973.

31 Comunicado oficial de la visita, Amae, leg. R-15336. 
La visita finalizaba con un alegato a la reciprocidad y a la asociación entre dos militares, representantes del ala más reaccionaria de los ejércitos y de los jefes de estado coetáneos. Posteriormente, Stroessner realizó viajes oficiales para encontrarse con los emperadores de Japón, los presidentes norteamericanos, con el francés Charles de Gaulle y fue el primer mandatario en visitar a Augusto Pinochet a finales de 1973, pocos meses después de su estancia en Madrid. Como es de sobra conocido, Franco no volvió a salir fuera de las fronteras desde los años cuarenta cuando se encontró con los jefes nazi-fascistas, pero mantuvo contactos con los mismos personajes que su homólogo paraguayo, confirmando de este modo la pertenencia a una amplia red de amistades políticas afines a estos sistemas antidemocráticos y represores.

\section{CONCLUSIONES}

La presencia de Stroessner en Madrid significaba el cierre del círculo de amistades iberoamericanas entabladas desde la década de 1940. El catálogo de visitantes se había iniciado en 1947 con Eva Perón e incluía casi todo el repertorio de las dictaduras del continente, una selección de invitados que muestra las preferencias políticas de la España franquista, aunque en realidad siempre estuvieron claras desde 1936 con la postura favorable que adoptó hacia los regímenes fascistas, antecedentes de las amistades en el exterior que nunca abandonó.

Las nuevas formas de fascismos y regímenes excluyentes en la Guerra Fría pasaron a ser las fórmulas políticas hacia las que Franco se inclinó, como lo prueba la deferencia hacia los países dirigidos por dictaduras militaristas, populistas o sistemas afines. La acción exterior hacia Iberoamérica, pues, no fue proyectada a todo el continente, sino únicamente a este tipo de naciones, generalmente coincidentes con las más protegidas por Estados Unidos en cuanto que eran las más firmes candidatas a frenar la extensión del comunismo en la región, y a doblegarse ante su superioridad económica y política. La propaganda y el exceso retórico dominaron en estas actuaciones políticas dirigidas a exhibir ante el mundo que Franco no estaba solo. 
Las visitas de Eva Perón, Trujillo y Stroessner tuvieron un contenido eminentemente político y propagandístico. La primera supuso una gran operación de imagen en el marco de la España aislada y la segunda, la comprobación de que el franquismo se asentaba en una gran red de países de carácter dictatorial. El encuentro con Stroessner, en cambio, fue un magnífico ejemplo de los últimos estertores del régimen en el que un dictador siniestro comparece ante uno de los viejos maestros de la represión y el control social en un tiempo en el que las formas políticas antidemocráticas resultaban anacrónicas. El denominado tardofranquismo recuperó parte de su perfil original y resultó capaz de recibir en Madrid, con todos los honores, a uno de los gobernantes latinoamericanos más represores. La acción exterior y la propaganda hacia Iberoamérica actuaron, pues, conjuntamente al servicio de la política interna del franquismo y de sus propósitos, entre los que figura la difusión de una imagen de Franco y de una España pacífica, próspera y al servicio del anticomunismo.

Recibido: 30 de junio, 2011. Aceptado: 9 de enero, 2012. 